\title{
Examination of the Effect of Badminton Education on Physical and Selected Performance Characteristics
}

\author{
Harun Genc ${ }^{1}$ \& Ghazwan Karaem $\mathrm{Ali}^{2}$ \\ ${ }^{1}$ High School of Physical Education and Sports, Bingol University, Bingol, Turkey \\ ${ }^{2}$ Libya 17 fibray School, Ankara, Turkey \\ Correspondence: Harun Genc, Selahaddin-i Eyyubi Mah. Üniversite Cad. No: 1 Posta Kodu: 12000 Bingöl, \\ Turkey. E-mail: hgenc@bingol.edu.tr
}

\author{
Received: September 3, $2019 \quad$ Accepted: October 6, $2019 \quad$ Online Published: October 24, 2019 \\ doi:10.5539/jel.v8n6p47 \\ URL: https://doi.org/10.5539/jel.v8n6p47
}

\begin{abstract}
This study was conducted on a total of 16 female students studying at the 1st grade of Bingöl University, School of Physical Education and Sports. Students participated in the study voluntarily and divided into 8 experimental groups (EG) and 8 control groups (CG). In the study, height, body weight, dominant hand grip strength, non-dominant hand grip strength, back strength, leg strength, 30-meter speed running, flexibility measurement, vertical jump, long jump tests were applied to the experimental and control groups as pre-test and post-test. Statistical analysis of the study was performed using SPSS 22.0 program. The analysis of the data in-group and intergroup measurements were performed by MANOVA and $\mathrm{p}<0.05$ was taken as statistical significance level. While there was no statistically significant difference between the experimental group and the control group in terms of pre-test measurement results, there was a statistically significant difference in body fat percentage, body weight, body mass index value in favor of EG in physical measurements after 8-week training. Also, in terms of performance characteristics, according to the post-test measurement results, the differences between experimental and control group dominant hand strength and non-dominant hand strength, $30 \mathrm{~m}$ speed average was significantin favor of EG, and again the difference between long jump and vertical jump tests was statistically significant in favor of EG in final test measurement results. As a result, it can be said that 8-week basic badminton training has positive effects on female students both physically and physiologically.
\end{abstract}

Keywords: female students, badminton education, physical characteristics, performance characteristics

\section{Introduction}

Each sport branch has its own work program, criteria and tests. In order to reach the highest level in a sporting competition, it is known that in addition to performing very laborious, long and tiring works, the scientific and technological developments brought by the age should be followed in the best way as well.

For this reason, countries know that all developments should be followed in the best way and they are in a cutthroat competition in all sports competitions. International competitions are rapidly diversifying and almost every country participates in competitions with a wide range of sports games. One of these sports games is badminton.

The popularity of badminton is increasing day by day and according to recent study, the number of badminton athletes worldwide is about 200 million (Demirci \& Demirci, 2010).

Badminton is an Olympic sport branch that is played on a net based on mutual kick with one-handed racket by two or four people without dropping the ball to the ground. In this sport, depending on the factors such as rationality, grace, speed, ability, mobility and the speed of reaction foreground, the game becomes very enjoyable (Demirci \& Paşa, 1994).

Since badminton is a sport that requires high level of physical performance, the physical characteristics of the players to be selected are of great importance. Badminton is more anaerobic, but aerobic capacity is also needed. Badminton is an Olympic sport based on quickness, mobility, reaction and aesthetics. Badminton, as in other racquet sports, has short-term maximal or submaximal loads and short-term rest periods. In this type of sports, especially speed, endurance, strength, coordination reaction, detection, game skills and technical success are considered as prerequisites. Badminton, a non-contact individual sport, requires splashes, moves, quick 
changeovers and quick arm movements (Demirci \& Demirci, 2010).

Physical, physiological and anthropometric parameters should be determined in terms of game characteristics of badminton. The reason for this requirement is that the coaches dealing with the badminton branch do not randomly select athletes. They must determine the athletes using the selection criteria appropriate to the badminton branch. They should also take into account the physical and physiological abilities prevailing in the badminton branch in the preparation of the training content and ensure that they are formulated according to their development order (Kafkas et al., 2009).

It is now indisputably important for Turkey to be successful in sports that the athletes representing our country must be determined in advance because training elite athletes requires quite a long term. As in all sport branches, on the basis of being successful in badminton comes the technical-tactical capacity and the condition of the player.

The common denominator in the definitions of badminton is that basic motoric properties are of great importance. Therefore, in order to help coaches, athletes, academicians and students who are involved in badminton, it is necessary to determine the basic motoric characteristics that badminton sport needs in general and again in this context to eliminate the dilemma of whether the dominant feature is basic motoric features or teaching of basic techniques. Physical and physiological tests are of great importance in the determination of all these.

The results of the study were thought to be important in terms of trainees, athletes, academics and students studying on training science, selecting new athletes in the badminton branch, and during the stepping of these athletes or creation of training content, physical fitness development.

The purpose of the study in the light of this information is to contribute to related the field and literature by determining whether the 8-week basic badminton training for female students studying in the same class and the same courses at the Physical Education and Sports Academy Sports Management Department who did not perform badminton sport before, has an effect on some physical, physiological and motoric properties.

\section{Method}

\subsection{Study Group}

This study was conducted with a total of 16 female at BingölUniversity, High school of Physical Education and Sports, 1. Class Coaching Education Department students who had never done badminton before.

\subsection{Research Design}

The voluntarily and randomly participant students of the study are divided into 8 experimental and 8 control groups. While the Experimental group was applying the determined badminton-training program 3 days a week approximately $80 \mathrm{~min}$., the control group participated in physical activities and only in-school theoretical and practical courses without specifying any branch. For measuring physical and physiological characteristics within the scope of initial (first measurement) and end of training (last measurement), Antropometric measures (heigh, weight), body mass index (BMI), body fat percentage (BFP), field measurements (dominant hand strength, non-dominant hand strength, back strength, leg strength, $30 \mathrm{~m}$ speed run, long jump, vertical jump, flexibility) standard tests of both groups were applied.

\subsection{Instruments for Data Collection}

\subsubsection{Anthropometric Measurements}

Length Measurement: Length measurements have been made with stadiometer with a sensitivity of $0.1 \mathrm{~cm}$ by making the subjects stop at a right angle with their bare feet, body weight is evenly distributed over the two feet, heels adjacent and in contact with the ground, after a deep breath while the arms are hanging freely from shoulder to side, bringing the ruler at the top of the head compressing the hair in a sufficient amount (Tamer, 2000).

Body Weight Measurement: It was made with Seca brand weighting instrument. During body weight measurement of subjects, they were wanted to be bare feet and having their tracksuits on while their body in the vertical position and body weight has been recorded in $\mathrm{kg}$ (Tamer, 2000).

Body Fat Ratio: The measurement of subcutaneous fat was made depending on the grounds of the fact $1 / 2$ of the body's total fat ratio is collected in fat stores below the skin and this is related to the total amount of fat. The name of the subcutaneous fat meter is skinfold caliper. The measurement of subcutaneous thickness was made by holding the skin and subcutaneous fat with the thumb and forefinger and pulling it away from muscle tissue in 
the direction of the natural skin fold. The clamping arms of the tool exert constant pressure on the skin. Thickness of double layer of skin and subcutaneous fat tissue are read in millimeters from caliber gauge (Günay et al., 2006). In this study, the fat measurement has been taken from two regions (hamstring, subscapularis). Body fat percentages were calculated from received data by using the following formula;

Body density, gm/ml =1.0852-0.0008 (suprailiac SF) -0.0011 (hamstring SF)

$\mathrm{SE}=0.0091$ Fat $\%=\left(\frac{4.95}{\text { Density }}-4.5\right) 100$ (Jackson \& Pollock, 1985).

Hamstring Skinfold Thickness Measurement: The measurement was made from midpoint between hip and knee joint, vertically, in front of the upper leg while the subject was standing, releasing leg muscles without contracting and values were recorded in mm (Tamer, 2000).

Subscapularis Skinfold Thickness Measurement: The measurement was made from $1 \mathrm{~cm}$ away from the lower angle of the shoulder blade of the diagonal line coming from the spine border while the subject was standing and waist in vertical position and body in a free position and values were recorded in mm (Tamer, 2000).

\subsubsection{Field Tests}

Strength Measurement: The aim of the test is to measure muscle strength. Muscular strength, the maximum power or strain generated by the muscle or muscle groups is measured by a dynamometer.

Hand Strength Measurement: Dominant and non-dominant hand strength measurements were made by Takei brand digital hand dynamometer instrument. Subject stood upright during measurement. The measurement was made in the position of without bending the measuring arm, at a slight distance from the body without contact. In the same condition, it is repeated twice for the dominant and non-dominant arm and the best value obtained was recorded (Günay et al., 2006).

Back Strength Measurement: The measurement was made by using Takei brand digital back and leg dynamometer. After the subject was given a period of warm-up time, he pulled the dynamometer bar vertically upwards in the position of standing, knees tense, placing his feet on the dynamometer stand, arms tense, straight back and body slightly bent forward. After 3 times repeat, the best value obtained was recorded as the measurement result in $\mathrm{kg}$ (Günay et al., 2006).

Leg Strength Measurement: Measurement was made by using back and leg dynamometer. After the subject was given a period of warm-up time, he pulled the dynamometer bar vertically upwards by using his legsin maximum rate, in the position of standing, knees twisted, placing his feet on the dynamometer stand, arms tense, straight back and body slightly bent forward (Günay et al., 2006).

Vertical Jump Test: The purpose of the test is to measure the vertical jump height. For the vertical jump test, the measuring table or a measuring system marked on the wall is required. The test is a measure of the distance between the most extreme point which the subject is able to reach with arm (soles completely on the floor) and the most extreme point by jumping. In the standing position, he was asked to jump and touch the highest point. The difference between the maximum first reach and the maximum jump of the subject was recorded in $\mathrm{cm}$, and by making two measurement, the best measurement result was recorded (Tamer, 2000).

Standing Long Jump Test: The aim of the test is to measure the explosive strength of the leg extensor muscles. The measurement was made between the toe at the starting line of the subject and the heel where the subject jumps and falls. By making two measurement, the best measurement result was recorded (Kula, 2019).

Flexibility (Sit-Reach) Test: The aim of the test was to measure hip and hamstring muscles and trunk flexibility. $35 \mathrm{~cm}$ in length, $45 \mathrm{~cm}$ in width, $32 \mathrm{~cm}$ in height stand's top surface dimensions were length $55 \mathrm{~cm}$, width $45 \mathrm{~cm}$. In sit-reach test, the athlete was asked to sit on the floor and to rest his barefoot evenly on the test stand. The athlete was asked to reach as far as he can with his hands in front of his body by leaning forward from his trunk without bending his knees. In addition, he was asked to wait 1-2 seconds at the last point he reaches. This application was repeated twice and the highest rating was recorded (Kula, 2019).

Measurement of The Speed (30 m): In this measurement (30 meters sprint), by determining distance, the subjects' speed measurement was made. Subjects were made run 2 times and their best ratings were taken. They took the exit position at the starting line in situation of slightly bent forward and with the start, subjects started to run at maximum speed. $30 \mathrm{~m}$ speed measurements were made by using Newtest 1000 photocell (Tamer, 2000).

\subsection{Statistics and Data Analysis}

The data obtained from the pre and post-training measurements of handball players were analyzed in the IBM 
SPSS 22 statistical program. Descriptive statistics are categorized according to all handball players and groups. The pre- and post-test distributions of the variables were examined according to groups, the normality of the distributions and the homogeneity of the variance were determined by the Mauchly's Sphericity Test and the Levene Test. Analysis of intergroup, intra group and the effect of training was carried out with multiple analysis of variance (MANOVA) in repeated measurements. Bonferroni test was used for Post Hoc comparisons, the significance level was accepted as 0.05 .

\section{Results}

The results of measurement of groups participating in study were summarized in the tables below.

Table 1. Descriptive statistics of participants and comparison of physical measurements among groups

\begin{tabular}{|c|c|c|c|c|c|c|c|}
\hline Group & $\mathbf{N}$ & Variables & Average \pm S.D & Min. & Maks. & & \\
\hline EG & 8 & Age (year) & $20.75 \pm 0.89$ & 20 & 22 & & \\
\hline $\mathrm{CG}$ & 8 & & $20.50 \pm 1.19$ & 19 & 22 & & \\
\hline EG & 8 & Height $(\mathrm{cm})$ & $165.06 \pm 11.67$ & 148.00 & 180.50 & & \\
\hline $\mathrm{CG}$ & 8 & & $163.75 \pm 13.68$ & 145.00 & 178.00 & & \\
\hline EG & 8 & BW (kg) & $54.19 \pm 3.70$ & 47.50 & 59.40 & & \\
\hline $\mathrm{CG}$ & 8 & & $53.09 \pm 3.44$ & 46.60 & 56.80 & & \\
\hline EG & 8 & BMI $\left(\mathrm{kg} / \mathrm{m}^{2}\right)$ & $20.05 \pm 1.81$ & 18.33 & 23.83 & & \\
\hline \multirow[t]{2}{*}{ CG } & 8 & & $19.27 \pm 2.17$ & 16.88 & 23.13 & & \\
\hline & & & & & & Chi Square $\left(X^{2}\right)$ & $\mathbf{p}$ \\
\hline \multirow[t]{4}{*}{ Toplam } & 16 & Age (year) & $20.63 \pm 1.02$ & 19 & 22 & 0.192 & 0.661 \\
\hline & & Height (cm) & $164.41 \pm 12.30$ & 145.00 & 180.50 & 0.100 & 0.752 \\
\hline & & BW (kg) & $53.64 \pm 3.49$ & 46.60 & 59.40 & 0.397 & 0.529 \\
\hline & & BMI $\left(\mathrm{kg} / \mathrm{m}^{2}\right)$ & $19.66 \pm 1.97$ & 16.88 & 23.83 & 1.103 & 0.294 \\
\hline
\end{tabular}

Note. Body Mass Index: BMI, Body Weight: BW.

$$
* \mathrm{P}<0.05 \text {. }
$$

As seen in Table 1, descriptive values of the subjects are specified in the table. Two participants in the study age, height, weight, bodymass index of the subject group (8 experimental group, 8 control group) averages are respectively $20.63+1.02$ years, $164.41+12.30 \mathrm{~cm}, 53.64+3.49 \mathrm{~kg}, 19.66+1.97 \mathrm{~kg} / \mathrm{m}^{2}$. Training period for all descriptive variables there's not any significant difference $(\mathrm{P}>0.05)$.

Table 2. Comparison of pre and post-test changes of physical features of groups

\begin{tabular}{|c|c|c|c|c|c|c|c|}
\hline Variables & $\mathrm{n}$ & Group & Pre-Test $\mathrm{X} \pm \mathrm{SS}$ & Post Test $\mathrm{X} \pm \mathrm{SS}$ & In-group Change (\%) & Test*Group F & $\mathrm{p}$ \\
\hline \multirow[t]{2}{*}{ Height (cm) } & 8 & EG & $165.06 \pm 11.67$ & $165.18 \pm 11.49$ & $0.12(0.07 \%)$ & 0.137 & 0.717 \\
\hline & 8 & CG & $163.75 \pm 13.68$ & $163.81 \pm 13.60$ & $0.06(0.04 \%)$ & & \\
\hline \multirow[t]{2}{*}{ BW (kg) } & 8 & EG & $54.19 \pm 3.70$ & $53.38 \pm 3.81$ & $-0.81(-1.49 \%)^{*}$ & 7.275 & $0.017^{*}$ \\
\hline & 8 & CG & $53.09 \pm 3.44$ & $52.95 \pm 3.11$ & $-0.14(-0.26 \%)$ & & \\
\hline \multirow[t]{2}{*}{ BMI $\left(\mathrm{kg} / \mathrm{m}^{2}\right)$} & 8 & EG & $20.05 \pm 1.81$ & $19.64 \pm 1.66$ & $-0.41(2.04 \%)^{*}$ & 22.208 & $0.000^{*}$ \\
\hline & 8 & CG & $19.27 \pm 2.17$ & $19.91 \pm 2.21$ & $0.06(03.32 \%)^{*}$ & & \\
\hline \multirow[t]{2}{*}{ BFP (\%) } & 8 & EG & $14.71 \pm 1.40$ & $13.25 \pm 1.37$ & $-1.46(9.92 \%)$ * & 39.384 & $0.000 *$ \\
\hline & 8 & $\mathrm{CG}$ & $15.29 \pm 0.99$ & $15.31 \pm 1.00$ & $0.02(\% 0.13)$ & & \\
\hline
\end{tabular}

Note. Body Mass Index: BMI, Body Weight: BW.

$* \mathrm{P}<0.05$.

Table 2, participants' height, body weight, body mass index, body fat percentage measurement results showing between groups, in-group and test * group relationship. The test * group interaction for the height property of the two groups is not meaningful for variables $(\mathrm{p}>0.05)$. While the change in the control group isn't statistically significant $(\mathrm{p}>0.05)$, body weight and body fat percentage on the experimental group shows a significant decrease $(p<0.05)$. Finally, in this table, there is a change in the body mass index value in both the experimental and control groups, the change in the control group is negative, the change in the experimental group is positive $(\mathrm{p}<0.05)$. 
Table 3. Comparison of pre- and post-test changes of dominant hand, non-dominantminant hand, back and leg strength tests among groups

\begin{tabular}{llllllll}
\hline Variables & $\mathrm{n}$ & Group & Pre-Test X \pm SS & Post Test X \pm SS & In-group Change (\%) & Test*Group F & p \\
\hline DHS $(\mathrm{kg})$ & 8 & EG & $32.35 \pm 5.91$ & $34.83 \pm 6.14$ & $\mathbf{2 . 4 8}(\mathbf{7 . 6 6 \%})^{*}$ & 42.834 & $0.000^{*}$ \\
& 8 & CG & $31.20 \pm 6.38$ & $31.23 \pm 6.46$ & $0.03(0.10 \%)$ & & \\
NDHS $(\mathrm{kg})$ & 8 & EG & $26.91 \pm 6.26$ & $28.90 \pm 6.43$ & $\mathbf{1 . 9 9}(\mathbf{7 . 3 9 \%})^{*}$ & 81.458 & $0.000^{*}$ \\
& 8 & CG & $26.71 \pm 6.06$ & $26.77 \pm 5.99$ & $0.06(0.22 \%)$ & & \\
BS $(\mathrm{kg})$ & 8 & EG & $86.47 \pm 12.49$ & $89.55 \pm 12.02$ & $\mathbf{3 . 0 8 ( 3 . 5 6 \% ) ^ { * }}$ & 214.406 & $0.000^{*}$ \\
& 8 & CG & $87.21 \pm 11.24$ & $87.18 \pm 11.27$ & $-0.03(-0.03 \%)$ & & \\
LS $(\mathrm{kg})$ & 8 & EG & $74.33 \pm 9.83$ & $81.46 \pm 10.19$ & $\mathbf{7 . 1 3}(\mathbf{9 . 5 9 \% ) *}$ & 10.558 & $0.006^{*}$ \\
& 8 & CG & $78.40 \pm 8.68$ & $78.55 \pm 8.65$ & $0.15(0.19 \%)$ & & \\
\hline
\end{tabular}

Note. Dominant Hand Strength: DHS, Non-dominant Hand Strength: NDHS, Back Strength: BS, Leg Strength: LS.

$* \mathrm{P}<0.05$.

As seen in Table 3, test * group interaction is being observed in all dominant hand strength, non-dominant hand strength, back and leg strength tests. The reason of this interaction is the development of experimental group ( $\mathrm{p}>$ $0.05)$.

Table 4. Comparison of pre- and post-test changes of $30 \mathrm{~m}$ speed run, long jump, vertical jump and flexibility tests among groups

\begin{tabular}{|c|c|c|c|c|c|c|c|}
\hline Variables & $\mathrm{n}$ & Group & Pre-Test $\mathrm{X} \pm \mathrm{SS}$ & Post Test $\mathrm{X} \pm \mathrm{SS}$ & In-group Change (\%) & Test*Group F & $\mathrm{p}$ \\
\hline \multirow[t]{2}{*}{$30 \mathrm{~m} \mathrm{SR}$ (sn) } & 8 & EG & $5.55 \pm 0.70$ & $4.69 \pm 0.51$ & $-0.86(15.49 \%)^{*}$ & 7.349 & $0.017 *$ \\
\hline & 8 & CG & $5.86 \pm 0.74$ & $5.82 \pm 0.68$ & $0.04(0.68 \%)$ & & \\
\hline \multirow[t]{2}{*}{$\mathrm{LJ}(\mathrm{cm})$} & 8 & EG & $164.38 \pm 17.07$ & $186.37 \pm 10.58$ & $21.99(13.38 \%)^{*}$ & 50.753 & $0.000 *$ \\
\hline & 8 & CG & $167.12 \pm 16.91$ & $167.31 \pm 16.84$ & $0.19(0.11 \%)$ & & \\
\hline \multirow[t]{2}{*}{$\mathrm{VJ}(\mathrm{cm})$} & 8 & EG & $33.38 \pm 4.96$ & $35.88 \pm 4.94$ & $2.5(7.49 \%)^{*}$ & 18.225 & $0.001 *$ \\
\hline & 8 & CG & $32.75 \pm 4.36$ & $33.13 \pm 4.99$ & $0.38(1.16 \%)$ & & \\
\hline \multirow[t]{2}{*}{$\mathrm{F}(\mathrm{cm})$} & 8 & EG & $28.88 \pm 6.63$ & $29.23 \pm 6.64$ & $0.35(1.21 \%)$ & 3.855 & 0.070 \\
\hline & 8 & $\mathrm{CG}$ & $29.06 \pm 4.97$ & $29.10 \pm 4.94$ & $0.04(0.13 \%)$ & & \\
\hline
\end{tabular}

Note. $30 \mathrm{~m}$ speed run: $30 \mathrm{~m}$ SR, Long Jump: LJ, Vertical Jump: VJ, Flexibility: F.

$* \mathrm{P}<0.05$.

As seen in Table 4, test * group interaction is being observed in $30 \mathrm{~m}$ speed run, long jump, and vertical jump tests. The reason of this interaction is the development of experimental group $(p>0.05)$. On the other hand, there is no significant change in the flexibility property values of groups in this table $(\mathrm{p}>0.05)$.

\section{Discussion and Conclusion}

In this conducted study, 8 students were used as experimental group and 8 students were used as control group. The study was conducted on a total of 16 women and the physical and physiological characteristics between the two groups were examined. In the study the followings were detectedin Table 1; the average age of the experimental group $20.75 \pm 0.89$ years, their average height length $165.06 \pm 11.67 \mathrm{~cm}$, their body weight average $54.19 \pm 3.70 \mathrm{~kg}$, their body mass index average $20.05 \pm 1.81 \mathrm{~kg} / \mathrm{m}^{2}$, the average age of the control group $20.50 \pm$ 1.19 years, their average height length $163.75 \pm 13.68 \mathrm{~cm}$, their body weight average $53.09 \pm 3.44 \mathrm{~kg}$, their body mass index average $19.27 \pm 2.17 \mathrm{~kg} / \mathrm{m}^{2}$. The differences among pre-test age, height, body weight and body mass index average of EG and CG were not statistically significant ( $p>0.05)$. According to these findings, it can be said that the two groups formed before the study were homogeneous.

Height is quite advantageous in terms of easy control of each region on the court in badminton. Tall badminton players use less effort to catch the ball than shorter players do (Omveer, 2017). In addition, the fact that males are approximately 10-15 cm taller than females may provide an advantage for males (Group, 2003). However, length is only one of the many factors affecting success in badminton and is not a critical determinant of success (Ooi et al., 2009). In the study conducted by Hotaman (2019), it is reported as the average height of girl athletes with an average age of $15.67 \pm 1.34$ years is $165.66 \pm 5.04 \mathrm{~cm}$, body weight is $54.25 \pm 3.95 \mathrm{~kg}$. Kandemir (2018) detected the height as $166.32 \pm 6.46 \mathrm{~cm}$, body weight as $54.21 \pm 6.08 \mathrm{~kg}$ for the average age of $17.64 \pm 2.68$ years female badminton players in his study. Pazarözyurt (2008) in his research on elite level female basketball athletes detected the height measurement of the playmaker as $1.78 \pm 0.04 \mathrm{~cm}$, the height measurement of 14 forwardsas $1.78 \pm 0.04 \mathrm{~cm}$, the height measurement of 14 pivots as $1.87 \pm 0.05 \mathrm{~cm}$. When the results are 
examined, although the studies related to badminton and our show parallelism, differences in height and body weight characteristics of some athletes draw attention. We thought that the resulting difference might be due to the changes in the applied sports branches. Because the physical and physiological structures of sports branches are different.

For badminton players, excess body weight and fat percentage limit the ability to move fast on the court and this is disadvantage in strokes that require bouncing (Reilly et al., 1990). It is reported that the appropriate body fat percentage for male badminton players should be between $10-15 \%$ and the body fat percentage suitable for female badminton players should be between $15-20 \%$ (Lieshout, 2002). In our study, when the pre-test and post-test results of the physical properties of the experimental group were examined in Table 2, there is no statistically significant differences in height value, however, there is a statistically significant decrease in the body weight and BFP values between experimental and control groups. On the other hand, Table 2 shows that both the experimental group and the control group had BMI changes, there is a significant positive change in BMI value pre-test and post-test values of the experimental group but there isa statistically significant negative change in BMI value in physical measurement pre-test and post-test values of the control group. In 1991, before and after training fat measurement tests were conducted on 15 control groups, 14 continuous running groups and 14 interval running groups performed as amateur athletes by Şenel (1998). At the result of these tests, the followings were detected; while the control group pre-training fat measurements were $18.17 \pm 4.70$, post-training fat measurements were $15.53 \pm 5.70$, while the continuous running group pre-training fat measurements test was $16.44 \pm 4.45$, after for 8 weeks, 3 times a week for $4.8 \mathrm{~km}$ with $80 \%$ intensity training, the fat measurements was $14.85 \pm 4.38$, while interval running group pre-training fat measurements test was $20.40 \pm 7.15$, training fat measurement was $17.72 \pm 7.63$. After 8 weeks, 3 times a week, $1.2 \mathrm{~km} 4$ sets $(4.8 \mathrm{~km})$ of $90 \%$ intensity. Within the scope of the study, a significant difference was found between the before and after training body fat ratios of the subjects subjected to different training contents. In 2003, Çolakoğlu found the average body fat measurement on 15 sedentaries before and after training. While body fat ratios before training was $28.76 \pm 5.59$, body fat ratios after 8 weeks of training was detected as $23.29 \pm 3.39$. A significant difference was found between preand post-training body fat ratios of the subjects involved in the study. In his study Ali (2011) detected that measurement of body fat ratios as $14.68 \pm 1.43 \%$ in the pre-test, $12.71 \pm 1.47 \%$ in the post-test for the control groupas $14.98 \pm 1.97 \%$ in the pre-test, $17.53 \pm 2.20 \%$ in the post-test for experimental group after 8 weeks experiments on 15 control and 15 experimental groups voluntarily and randomly selected from sports management department 30 female students who have never played badminton before. As seen in Table 2, when the pre-test and post-test values are analyzed according to the result of our study. These results can be attributed to the fact that the control group did not train any. Moreover, in the experimental group, we can say that there is a significant decrease in the body weight, BMI and BFP values of the students due to the training.

Badminton is a strength related sport and a high degree of leg, back, wrist, elbow and shoulder strength are needed during the match (Omosegaard, 1996). In our study, as seen in Table 3, test* group interaction for all variables all meaningful for variables (dominant hand strength, non-dominant hand strength, back strength, leg strength characteristics). These interactions within the experimental group development. In a study conducted on university female badminton players, it was stated that badminton training leads to an increase in strength (Turgut et al., 2017). In the study investigating the effect of 12-week basic badminton training on motor functions statistically significant difference was found between the first and last handgrip strength measurements of the experimental group (Polat, 2009). In a study investigating some physical and physiological characteristics of national badminton players and amateur badminton playersit is stated that because of national badminton players do more training their hand grip strength is higher (Kafkas et al., 2009). In addition, in another study, some physical and physiological characteristics of young national badminton players and amateur badminton players were compared and it was reported that elite female athletes had better strength characteristics (Güçlüöver, 2012). These studies support our study. We can say that regular badminton training increases the strength characteristics positively.

The speed is ability to move the arms and legs very quickly during dunking or defenseand is one of the most important components of high-level badminton players (Tiwari \& Rai, 2011). In badminton players, speed is evaluation of the situation by grasping quickly beyond the rapid response and action, rapid orientation, running and stopping. As shown in Table 4, test * group interaction was observed at a speed of $30 \mathrm{~m}$. development in our study. This interaction within the experimental group development. Kaya (2015), in the study of the effects of different training methods on physical physiological and technical capacities of children in football, reported that the 8-week training in small-field games made a statistically significant difference in the 10 and $30 \mathrm{~m}$ sprint values of the subjects. Ali (2011) reported that he found significant improvements in speed characteristics of the 
experimental group, which was applied the 8-week basic badminton training. These studies support our study. 8 -week regular badminton training can be said to have a positive effect on speed characteristics.

Badminton is a highly explosive sport on a small playground that requires very fast movement and requires high explosive properties of both the lower and upper extremity muscles (Hughes, 1995). As seen in Table 4 in our study, there were test $*$ group interactions for the long jump and vertical jump tests in our study. These interactions within the experimental group development. Kaya (2015) in the study of the effects of different training methods on physical physiological and technical capacities of children in football reported that he detected the 8-week training in small-field games in football made a statistically significant difference in the vertical jump values of subjects. Malatesta and his friends (2003) in their study stated that 4-week training program made a significant increase in the vertical jump height of volleyball players $(p<0.05)$. In the conducted by Uğraş and his friends (2002) among 18 amateur football athletes while the average of vertical jump pre-test was found as $0.47 \mathrm{~m}$., after the 10 -week training period, the post-test was detected as $0.51 \mathrm{~m}$. Among the first and after 10-week training vertical jump post-test averages of the football players tested, significant difference was found. Ali (2011), in his study, in the 8-week badminton training program applied experimental group, detected long jump test values as $170.20 \mathrm{~cm}$ in the pre-test and as $182.33 \mathrm{~cm}$ in the post-test. In addition, he cites there was a significant difference between the two measurements, but no difference in the control group. These studies support our study. We can say that regular 8-week basic badminton training improves long jump and vertical jump characteristics.

Badminton players who have flexibility can perform different strokes accurately and effectivelyin the most difficult situations and under stress in the game. The weakness of the strokes at the head height is due to insufficient flexibility of the core muscles (Omosegaard, 1996). For flexibility feature test* group interaction is not significant in our study. There is no difference between group comparisons between the pre and post measurements. Yenal and his friend (1999) found a statistically significant difference in the experimental group compared to the control group in terms of the flexibility feature of physical education activities, which included the flexibility studies, on children aged 10-11 $(\mathrm{p}<0.05)$.Saygin and his friends $(2004)$ reported that they found a statistically significant difference in flexibility between children with mild activity and those with moderate severity $(\mathrm{p}<0.05)$. These studies do not show similarity with the result of the flexibility test of our study. When we examine the information in the literature, it is mentioned that it can be developed at the most appropriate level when it is operated with appropriate methods and contents for at least 6 weeks for the development of flexibility (Weineck, 2011). Considering this information, the reason for the difference in flexibility between our study and other studies can be explained by the fact that the subjects in the literature conducted regular training including flexibility studies, and in our study, the absence of flexible studies.

Badminton is an individual sport which is played at low and medium tempo, but with the intervals and high repetitions of the moves and strokes, that makes the game win. In addition to being aware of the physical characteristics of badminton athletes, a thorough analysis of the relationships between physiological measurement values of the athletes and the final results of the match will help the coaches to plan and organize more appropriate and special trainings according to the characteristics of the high-intensity actions that will win the competition. It is stated in the literature that regular exercises will increase the diameter of the muscles and thus increase the strength of the muscles and energy stores of the muscles and increase the number of capillary vessels as well as improve the endurance of muscles. It is also stated that the speed feature will be positively affected by the increase in the contraction rate by the warnings providing quickness (Demir \& Filiz, 2004).

In the light of this information, while no statistically significant difference was found between the experimental and control group pre-test measurement results, a negative significant difference in BMI, in Table 2, also an increase of body weight and BFP values in negative direction was detectedin the evaluation of the results of the pre-test and post-test of control group in scope final test after 8 weeks of training. On the other hand, in the experimental group, a statistically significant change in body weight, BMI and BFP values were observed, again, when looked at Table 1, positive change in body weight, BMI and BFP values were observed. Among experimental and control groups dominant hand strength, non-dominant hand strength, back strength, leg strength, $30 \mathrm{~m}$ sprint, long jumpand vertical jump measurement, statistically significant differences were found in favor of the experimental group. In addition, it can be seen clearly that the applied training improves both physical and selected performance characteristics to a significant level. When the results in the literature and our study are taken into consideration, it can be thought that both the elite and the regular trainings have positive effects on both physical development and performance characteristics of the individuals.

As a result, it can be said that the 8-week basic badminton training which applied to female athletes had a positive effect both physically and physiologically. 


\section{References}

Ali, G. K. (2011). The Effect of 8-Week Basic Badminton Training on Some Physical and Physiological Parameters Applied to Female Students. Gazi University, University of Health Sciences Department of Physical Education and Sports, Master Thesis, Ankara.

Çolakoğlu, F. F. (2003). Effects of Eight-Week Aerobic Exercise Program on Some Physical Physiological and Blood Parameters of Sedentary Middle-Aged Women. PhD Thesis. Ankara: Gazi University.

Demir, M., \& Filiz, K. (2004). Effects of sport exercises on human organism. Gazi University Kırşehir Faculty of Education, 5(2), 110-113.

Demirci, A., \& Demirci, N. (2010). Badminton Games. Ankara: Spor Publishing House.

Demirci, B., \& Paşa, S. (1994). Tüytop Badminton. Magazin Journal, 17, 3-4.

Group, D. (2003). Step by Step Tenis \& Other Raeket Sports. London: Diagrow Visual İnformation Limited.

Günay, M., Tamer. K., \& Cicioğlu, İ. (2006). Sport Physiology and Performance Measurement. Ankara, Baran Ofset.

Güçlüöver, A. (2012). Analysis of somestrength, strengthandagilitycharacteristics of young national badminton players and amateur badminton players. Kirıkkale University Institute of Health Sciences: Unpublished master'sthesis.

Hotaman, F., Özgür, B., \& Coşan, F. (2018). The Relationship Between the Simple Errors of National Badminton Players During the Competition and Their Physical Performance. Sports Science Research Journal, 3(1), 73-84. https://doi.org/10.25307/jssr.397508

Hughes, M. G. (1995). Physiological demands of training in elite badminton players. In T. Reilly, M. Hughes \& A. Lees (Eds.), Science and Racket Sports (2nd ed., pp. 38-43). London: E and FN Spon.

Jackson, A. S., \& Pollock, M. L. (1985). Practical assessment of body composition. Phys Sportsmed, 13, 76-90. https://doi.org/10.1080/00913847.1985.11708790

Kafkas, M. E., Taşkıran, C., Arslan, C., \& Acak, M. (2009). Comparison of Some Physical, Physiological and Anthropometric Parameters of Young National and Amateur Badminton Players. Journal of Physical Education and Sport Sciences, 3(1).

Kandemir, C. (2018). Comparison of Mental Rotation Reaction Time and Dynamic Balance Test Success Levels in Advanced Badminton Players. Master Thesis, University of Uludağ, Institute of Educational Sciences, Department of Physical Education and Sports, Bursa.

Kaya, M., Genç, H., \& Müniroğlu, S. (2017). Comparison on Effects of Various Exercise Methods in Football on Children's Some Physical, Physiological and Technical Capacity. The Anthropologist, 27, 37-43. https://doi.org/10.1080/09720073.2017.1311686

Kula, H. (2019). Talent Selection and Principles in Sports. Ankara, Gazi Bookstore.

Lieshout, K. A. V. (2002). Physiological profile of elite junior badminton players in South Africa. Doctoral Dissertation, University of Johannesburg.

Malatesta, D., Cattaneo, F., Dugnani, S., \& Maffiuletti, N. A. (2003). Effects of electromyo stimulation training and volleyball practice on jumping ability. Strength Cond. Res., 17(3), 573-579. https://doi.org/10.1519/00124278-200308000-00025

Omosegaard, B. O. (1996). Physical training for badminton (pp. 3-32). Denmark: MallingBeck.

Omveer. (2017). A study on prediction of playingability in badminton from selected anthropometrical physical and physiological characteristics among inter collegiate players. International Journal of Advanced Researchand Development, 2(5), 50-54.

Ooi, C. H., Tan, A., Ahmad, A., Kwong, K. W., Sompong, R., Ghazali, K. A., ... Thompson, M. W. (2009). Physiological characteristics of elite andsub-elite badminton players. Journal of Sport Science, 27(14), 1591-1599. https://doi.org/10.1080/02640410903352907

Pazarözyurt, İ. (2008). Examination of Anthropometric Properties, Vertical Jump and Spine Flexibility in Elite FemaleBasketball Players University of Çukurova. Health Sciences Institute, Department of Physical Education and Sports, Master Thesis, Adana.

Polat, G. (2009). The Effects of 12-Week Basic Badminton Training Training on Motoric Functionsand Reaction 
Times in Children of 9-12 Age Group. Cukurova University Institute of Health Sciences, Master Thesis, Adana.

Reilly, T., Secher, N., Snell, P., \& Williams, C. (1990). Physiology of sports (1st ed.). London: E \& FN Spon.

Saygın, Ö., \& Mengütay, S. (2004). Evaluation of Physical Activity Levelsand Intensity of Physical Activity of Girls and Boys. Journal of Sport and Medicine, 1, 12.

Şenel, Ö. (1998). The Effects of Physical Fitness Activities Integrated on the Physical and Physiological Parameters of Primary School Physical Education Course Curriculum. Gazi Beden Eğitimi ve Spor Mag., 4, 27-34.

Tamer, K. (2000). Measurement and Evaluation of Physical and Physiological Performance. Ankara: Bağırgan Publishing House.

Tiwari, L. M., \& Rai, V. (2011). Srinet S. Relationship of selected motor fitness components with the performance of badminton player. Asian J Phys Educ Comput Sci Sports, 5(1), 88-91.

Turgut, M., Aydın, R., \& Erkılıç, A. O. (2017). The Effects of 8-Week Classic Badminton Training on Some Physical Performance Parameters of Female Athletes from the Badminton Team of Bartın University. UKSAD, 3(2), 354-364.

Uğraş, A., Özkan, H., \& Savaş, S. (2002). Physical and Physiologica 1 Characteristics of Bilkent University Football Team After 10-Week Preparation. Journal of Gazi Education Faculty, 22, 1.

Weineck, J. (2011). Fitness Training in Football Tanju Bağırgan (Trans., pp. 15-330). Ankara Sports Publishing and Bookstore.

Weineck, J., Elmacı, S., \& Yaman, H. (1998). Sports anatomy. Ankara: Bağırgan Publishing House.

Yenal, T. H., Çamliyer, H., \& Saraçoglu, A. S. (1999). The Effect of Physical Education and Sport Activities on Motor Skills and Abilities in Secondary School Children. Gazi Journal of Physical Educationand Sports, 4, $15-24$.

Zorba, E., \& Ziyagil., M. A. (1995). Body Composition and Measurement Methods. Trabzon, Gen Typography Advertising Ltd. Şti.

\section{Copyrights}

Copyright for this article is retained by the author, with first publication rights granted to the journal.

This is an open-access article distributed under the terms and conditions of the Creative Commons Attribution license (http://creativecommons.org/licenses/by/4.0/). 